\title{
Interação e Interatividade através das interfaces de materiais educacionais digitais
}

\author{
Paula Caroline Schifino Jardim Passos - UFRGS - paulacarolinejardim@ gmail.com \\ Patricia Alejandra Behar - UFRGS - pbehar@terra.com.br
}

Resumo: Este artigo trata da relação entre a interface de um material educacional digital e as formas de interação entre aluno e conteúdo que esse dispositivo pode possibilitar. Para tanto, são apresentadas as definições de interface, de interação e de interatividade e argumenta-se a respeito da influência delas para a aprendizagem do aluno. Piaget $(1974 ; 1996)$ postula que o conhecimento não procede nem do sujeito nem do objeto, mas é construído no caminho entre os dois, dependendo tanto de um, como de outro. Considerando o aluno como sujeito e a interface como objeto, a interface é colocada, neste caso, em igualdade de importância com o aluno. Pretende-se refletir a respeito da influência da interface na maneira como o aluno se apropria do conteúdo e como isso se reflete em seu aprendizado.

Palavras-chave: interface, interação, interatividade, material educacional digital

Abstract: This article addresses the relationship between the interface of a digital educational material and the forms of interaction between student and content that can be enabled by this device. To this end, the interface definitions, interaction and interactivity are presented, and it argues about the influence of these to student learning. Piaget $(1974,1996)$ postulates that knowledge does not come only from the subject or the object, but it is built and dependent on both. Considering the student as subject and the interface as object, the interface is placed on equal importance with the student. The intention is to reflect on the influence of the interface in the way the student appropriates the content and how this is reflected in their learning.

Keywords: interface, interaction, interactivity, digital educational materials

\section{Introdução}

As inovações tecnológicas constantes são realidade na vida atual e têm ocorrido em prazos cada vez mais curtos de tempo. Em termos de Educação, essa evolução se reflete na proliferação de recursos digitais para cursos a distância ou mesmo para apoio a cursos presenciais. Os materiais educacionais digitais (MEDs) surgem em diversos formatos e já fazem parte do cotidiano escolar e acadêmico. Este artigo usa a expressão MED para se referir a "todo material didático elaborado com objetivos relacionados à aprendizagem e que incorpora recursos digitais" (Behar, 2009, p.33). Entende-se a aprendizagem como o processo no qual o indivíduo constrói o próprio conhecimento através da interação com o meio (Piaget, 1974).

O motivo para o interesse nos MEDs está nas possibilidades multimídia que oferecem, como exibição de imagens, vídeos, simulações, sons, entre outros. O portal do Ministério da Educação (MEC) ${ }^{1}$, em relação à escola do século 21, declara que "o livro didático não é mais suficiente para um ensino de qualidade. Os recursos multimídia são importantes no dia-a-dia da sala de aula, o que faz da aprendizagem um processo mais em sintonia com a realidade dos alunos desta nova sociedade da informação". 
O recurso digital é, em essência, voltado à ação do usuário, diferentemente das mídias anteriores, expositivas, como o rádio e a televisão. Assim, permite-lhe escolher um caminho, navegar pelo material e ler o conteúdo na ordem em que desejar, como se escrevesse seu próprio texto. Essa característica é adequada às práticas educacionais, já que a posição ativa do aluno contribui para a construção do conhecimento.

Não é suficiente, no entanto, que os MEDs sejam meramente agregados ao contexto educacional. É preciso que haja projetos para sua concepção e aplicação, definindo a proposta pedagógica, os conteúdos e as mídias que apresentarão melhores resultados para os objetivos propostos. Os recursos digitais devem ser inseridos como ferramentas de apoio à aprendizagem mediante planejamento que considere tanto questões pedagógicas, quanto técnicas.

Dentre as questões técnicas a serem consideradas para o desenvolvimento de um MED está o design da interface. Entende-se, neste estudo, que a interface de um material é a superfície que possibilita o contato entre usuário e conteúdo, ou entre usuário e usuário (no caso de estarem conectados em rede) e permite o acesso às funções do sistema. Assim, pode influenciar na maneira como o aluno se apropria do conteúdo e, também, pode interferir em sua aprendizagem.

Este artigo trata da relação entre a interface de um MED e as possibilidades de interação entre aluno e conteúdo. As próximas seções apresentam as definições de materiais educacionais digitais e de interface, seguidas de uma reflexão referente a interação, interatividade e aprendizagem através de recursos digitais.

\section{Materiais Educacionais Digitais e Interação}

Os MEDs podem apresentar-se em diversos formatos, cada um deles oferecendo vantagens específicas às práticas pedagógicas. Um dos formatos de MED mais comuns são os objetos de aprendizagem. Existem diversas definições para objetos de aprendizagem. O site da Rede Interativa Virtual de Educação (RIVED) considera como tal "qualquer recurso que possa ser reutilizado para dar suporte ao aprendizado" 2. O Institute of Electrical and Electronics Engineers (IEEE, 2002) tem uma definição mais ampla, que considera como objetos de aprendizagem "quaisquer entidades, digital ou não digital, que podem ser usadas, reutilizadas ou referenciadas durante a tecnologia de suporte de aprendizagem" 3 .

Esta pesquisa utiliza a definição que consta em Behar (2009) a qual caracteriza os objetos de aprendizagem como recursos autônomos, utilizados em módulos que podem ser incorporados a múltiplos aplicativos e adaptados a diversos contextos e públicos. Podem, dessa forma, ser considerados objetos de aprendizagem quaisquer materiais eletrônicos (como imagens, vídeos, páginas web, animações ou simulações) desde que tragam informações destinadas a construção do conhecimento e guardem a característica de possibilidade de reutilização através da padronização.

Para que um material possa ser reutilizado é preciso que seja construído segundo um padrão de metadados. Essa descrição permitirá seu armazenamento em um repositório e sua posterior recuperação. Como padrões conhecidos mundialmente podese citar: LOM $^{4}$, ARIADNE ${ }^{5}$ IMS $^{6}$ e SCORM ${ }^{7}$.

Além da reusabilidade, outras características desejáveis aos objetos de aprendizagem são a acessibilidade, a interoperabilidade, a durabilidade e a customização. Acessibilidade é a possibilidade de acesso remoto ao objeto, enquanto interoperabilidade se refere sua a articulação em diferentes plataformas e agregado a diferentes ferramentas. A característica de durabilidade é relativa à vida útil do material em termos tecnológicos, o que tem relação com a possibilidade de customização, ou a 
flexibilidade do material em termos de adaptação para novas aplicações (Tarouco, Fabre e Tamusiunas, 2003); (Martins, B; Winckler, R, 2004).

Quando disponibilizados na rede mundial de computadores, os objetos de aprendizagem permitem a abertura a uma imensidão de ligações com informações complementares, publicadas em qualquer lugar do mundo. Nesse contexto, possibilitam diversas conveniências para professores e alunos, como por exemplo: acesso livre ao conteúdo a qualquer momento e de qualquer lugar, facilidade na atualização das informações, quantidade de espaço ilimitado e baixos custos de produção e publicação. Porém, os maiores atrativos para a aprendizagem do aluno estão nos recursos interativos que esses materiais podem apresentar. Esse assunto será abordado na seção 4 deste artigo.

\section{Interface}

O "Dicionário de informática e internet" de Sawaya (1999) define interface gráfica da seguinte forma: "Um tipo de configuração de imagens de vídeo que permite ao usuário ${ }^{8}$ selecionar comandos, acionar programas e ver listas de arquivos ou opções, apontando para representações figurativas (ícones) e listas de itens de menus na tela."

Os primeiros computadores existentes eram projetados por engenheiros, para seu próprio uso. As interfaces eram diretas, com painéis compostos de chaves e mostradores que controlavam os registros internos. $\mathrm{O}$ design de interface surgiu com o advento dos monitores (VDUs - visual display units) e das estações de trabalho pessoais (Grudin, 1990 apud Preece, Rogers e Sharp, 2005).

A interface gráfica do usuário (Graphical User Interface, GUI) foi desenvolvida pelo Palo Alto Research Center da Xerox, na década de 1970, e em seguida popularizada pela Macintosh da Apple. Johnson (2001) considera que a adoção generalizada da GUI foi responsável por uma grande mudança na maneira como os seres humanos e os computadores interagem e expandiu em muito a sua capacidade de usá-los. Isso porque a GUI libertou-as da sintaxe misteriosa das arcaicas "linhas de comando".

Johnson (2001) define a interface de forma simples comparando-a a um tradutor, que torna as partes uma sensível a outra. Ele afirma que a relação mediada pela interface é semântica, caracterizada por significado e expressão. Assim, os computadores, que trabalham por pulsos de eletricidade (que representam estado de ligado ou desligado em 0 ou 1), precisam representar-se ao usuário em uma linguagem que este compreenda, formada por palavras, conceitos, imagens, sons e associações.

Segundo Cybis, Betiol e Faust (2007) as interfaces atuam como ferramentas cognitivas porque podem modelar representações, abstrair dados e produzir informações. Dessa forma, são artefatos capazes de facilitar a percepção, o raciocínio, a memorização e a tomada de decisão, tanto para atividades de trabalho quanto para divertimento. Através de painéis com informações, dados, controles, comandos e mensagens, a interface solicita e recepciona as entradas de dados, de controles e de comandos dos usuários, assim, controla o diálogo, interligando as entradas dos usuários com as apresentações de novos painéis. Eles definem, ainda, a interface como "[...] um componente do sistema interativo formado por apresentações e estruturas de diálogo que lhe conferem um comportamento em função das entradas dos usuários ou de outros agentes externos" (Cybis, Betiol e Faust, 2007, p.17).

Para Lévy (1993) as interfaces são aparelhos e materiais que permitem a comunicação entre um sistema informático e os humanos. Esses dispositivos podem ser entendidos como superfícies que fazem ligação entre usuário e sistema, transmitindo 
informações e permitindo acesso às funcionalidades.

A interface pode influenciar na maneira como o usuário percebe e se apropria do conteúdo contribuindo para um bom desempenho nas atividades, ou pelo contrário, impedindo ou inviabilizando os processos cognitivos. Lévy (1993) ainda afirma que a interface interfere no modo de captura da informação, orientando a significação e a utilização de uma mídia. Ele afirma que "a memória humana é estruturada de tal forma que nós compreendemos e retemos bem melhor tudo aquilo que esteja organizado de acordo com relações espaciais. Lembremos que o domínio de uma área do saber implica quase sempre, a posse de uma rica representação esquemática” (1993, p. 40).

$\mathrm{Na}$ interface são criadas condições para que ocorram interações entre sujeito e objeto (Piaget, 1974). Assim, no caso de trabalho com MEDs, entende-se que a interface, apresentando característica de interatividade, estará diretamente ligada a aprendizagem do aluno. Esse é o tema que será desenvolvido na próxima seção.

\section{Interação, Interatividade e Aprendizagem}

A interação, descrita em Piaget (1996), refere-se à relação entre indivíduos, no sentido de "ação entre" sujeito e objeto, da qual se origina o conhecimento. Assim, o conhecimento não procede nem do sujeito nem do objeto, mas é construído no caminho entre os dois, dependendo tanto de um, como de outro.

"[...] o conhecimento não procede, em suas origens, nem de um sujeito consciente de si mesmo nem de objetos já constituídos (do ponto de vista do sujeito) que lhe imporiam: resultaria de interações que se produzem a meio caminho entre sujeito e objeto, e que dependem, portanto, dos dois ao mesmo tempo, mas em virtude de uma indiferenciação completa e não de trocas entre formas distintas." (Piaget, 2007)

Filatro (2009) explica que, para Piaget, o desenvolvimento do individuo depende da formação de estruturas mentais (chamada de assimilação). Ao entrar em conflito com as estruturas mentais previamente formuladas, a nova informação provoca um desequilíbrio. Na busca de harmonia, são desenvolvidas novas estruturas mentais. Dessa forma, o ser humano muda sua representação do mundo para que este se molde a seu modo de pensar, o que gera uma adaptação, ou então, muda seu modo de pensar para que se encaixe no mundo, o que resulta em acomodação. $\mathrm{O}$ equilíbrio dos esquemas mentais é, assim, o motor do desenvolvimento humano e se dá pela experiência com objetos e pessoas.

Piaget $(1974 ; 1996)$ também postula que o conhecimento não seja resultado de simples observação, não sendo cópia da realidade. Tampouco se encontra totalmente determinado na mente do indivíduo, mas é, na verdade, o produto de uma interação entre estes dois elementos. Depende, então, de ação do indivíduo sobre o objeto, e consequente interiorização dessa ação.

Considerando o aluno como sujeito e a interface como objeto, a interface é colocada em igualdade de importância com o aluno. Dessa forma, o estudo da interface torna-se fundamental para o processo educativo. Sendo que a observação não é suficiente para trazer conhecimento, dependendo da ação do individuo para a interiorização, a interface precisa permitir essa ação. É necessário, então, que os materiais educacionais digitais sejam planejados e construídos visando a possibilitar uma postura ativa do sujeito. A Figura 1 representa a interação que se dá entre sujeito (aluno) e objeto (conteúdo representado na interface do computador). 


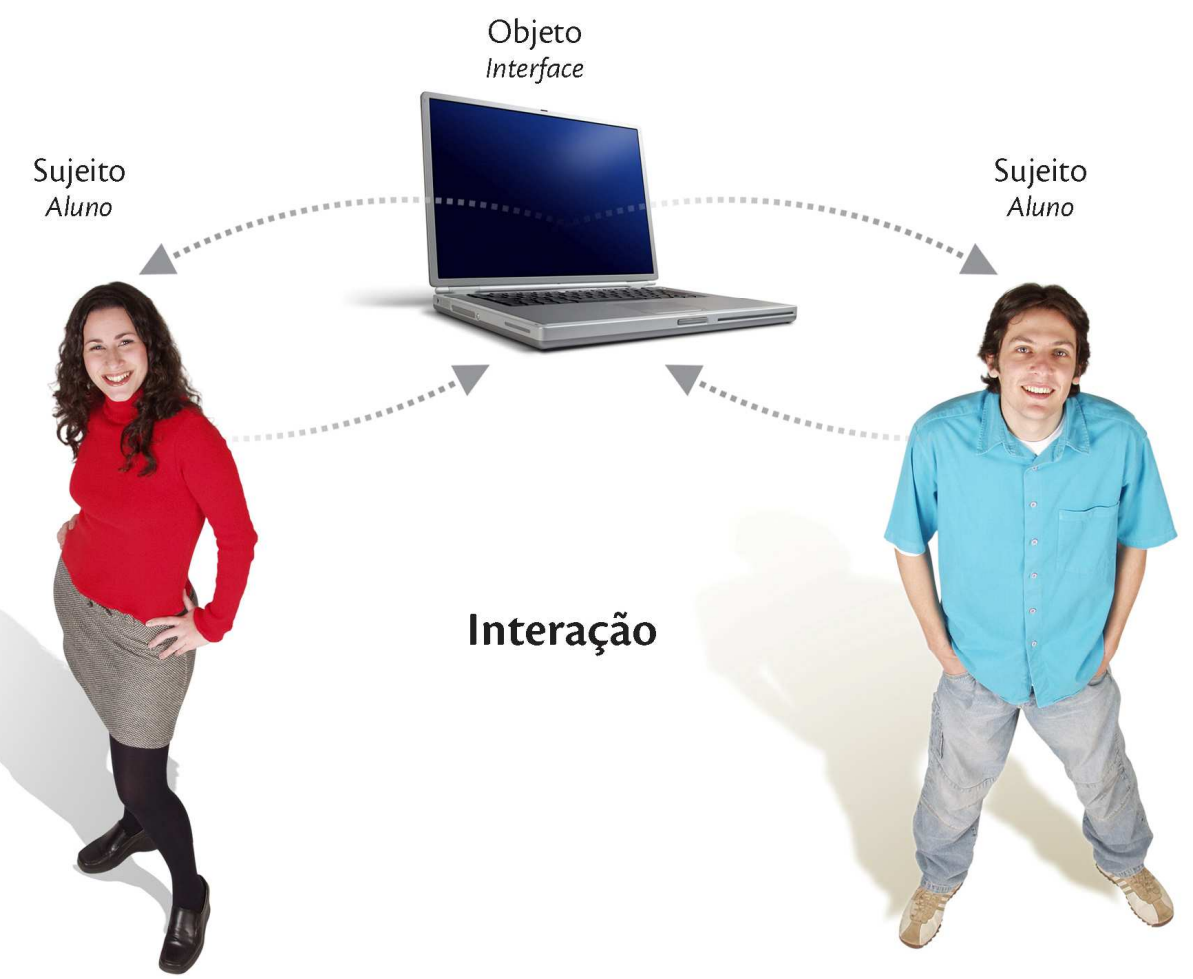

Figura 1: Interação entre alunos e conteúdo através da interface

Citando Laurel (1993), Lemos (2002, p.118) afirma que interação "não só é um modo de conversação e conexão, [...] mas um contexto onde as partes são agentes engajados em ações”. Já, interatividade para Lemos (2002, p.119) representa uma nova qualidade de interação a que define como "ação dialógica entre o homem e os objetos tecnológicos".

Filatro (2008) afirma que, no aprendizado eletrônico, a interação não acontece por acaso, mas precisa ser intencionalmente planejada e expressa visual e funcionalmente na interface do curso ou unidade de aprendizagem. Para ela, interação diz respeito ao comportamento das pessoas em relação umas às outras e ao sistema, estando ligada à ação recíproca pela qual os indivíduos e objetos se influenciam mutuamente.

Já a interatividade para Filatro (2008) descreve a capacidade potencial do sistema de proporcionar interação. Assim, segundo ela, pode-se dizer que experiências de aprendizagem significativas serão proporcionadas se a solução educacional projetada for, antes de tudo, interativa. Isso significa disponibilizar uma interface que possibilite interação e ofereça atividades de aprendizagem que exijam do aluno a interação com conteúdos, com a ferramenta e com outras pessoas.

Michael Moore (1989) destaca três tipos de interação: aluno/professor, aluno/aluno, e aluno conteúdo. A interação em um MED pode ser classificada como aluno/conteúdo, por esse motivo este artigo focará nessa modalidade. Segundo o autor citado, a interação entre aluno e conteúdo, ou tema de estudo, é essencial para educação já que é através desse processo que ocorrem mudanças na compreensão, perspectiva e estruturas cognitivas da mente do aluno. Ele afirma que esse tipo de interação está envolvida, ao menos parcialmente, com o que Holmberg (1986) chama de "conversa interna didática", que é quando os alunos "falam para si mesmos" sobre as informações e ideias que encontram em um texto, um programa de televisão, uma palestras, ou em um outro lugar. 
Moore (1989) continua afirmando o texto didático como a mais antiga forma de facilitar a interação com os conteúdos na educação e interação a distância. Ele declara que nos tempos medievais os textos não tinham a função de informar, nem de divertir, mas de instruir. O uso de técnicas de impressão para o ensino, no século XIX, permitiu a invenção de guias de estudo com textos e explicações para serem lidos em casa. A seguir, os alunos passaram a interagir com conteúdos transmitidos em programas de rádio e televisão e com gravações eletrônicas em fitas de vídeo e software de computador. Até o ano dessa publicação de Moore, o videodisco interativo era a forma mais avançada de interação didática inventada.

Mais recentemente, Mattar (2009) ressaltou que, com as tecnologias modernas, particularmente a Internet, é possível desenvolver conteúdos e objetos de aprendizagem em vários formatos como: som, texto, imagens, vídeo e realidade virtual. Nesses casos, o aluno pode interagir com o material de muitas formas: navegando e explorando, selecionando, controlando, construindo, respondendo... e pode, inclusive, personalizar o conteúdo e contribuir para o aperfeiçoamento do material utilizado em um curso.

Machado Júnior (2008) olha criticamente a questão do emprego das tecnologias na educação. Ele defende que se deve evitar o caráter instrucional e as formas passivas de interação aluno/conteúdo. A internet, possibilitando o hipertexto ${ }^{9}$ fornece um caminho para os mais diferentes assuntos, atividades em laboratórios virtuais e aulas com conteúdo interativo que podem despertar potencialidades e o espírito questionador dos estudantes. Assim, ele acredita que a postura passiva ou ativa que o estudante pode assumir depende da fundamentação pedagógica envolvida e das estratégias didáticas adotados pelo educador.

Silva e Fernandes (2007), por sua vez, consideram que, quando propostos sob uma perspectiva interacionista, os materiais podem valorizar a ação, a reflexão crítica, a curiosidade, o questionamento exigente, a inquietação e a incerteza. Assim, podem ser potencializados os processos de ensino e aprendizagem, bem como o pensamento divergente, o confronto, a análise, a capacidade de compor e recompor dados e a argumentação. Nesse mesmo sentido, Lévy (1993) afirma que a multimídia interativa é adequada aos usos educativos, pois a ausência de uma linearidade favorece a atitude exploratória e lúdica do aluno frente ao material. Assim, permite-se o seu envolvimento pessoal no processo de aprendizagem.

Sims (1997) declara que a ideia de interação está intrínseca à prática efetiva de ensino e a descoberta individual. Assim, a interatividade pode ser percebida como uma arte, pois envolve uma gama de aptidões, que incluem: a compreensão do aluno, as capacidades da engenharia de software, um design instrucional rigoroso e a aplicação de interfaces gráficas adequadas. Ele afirma não ser adequado que a atividade educacional esteja limitada a produtos onde a interatividade é trivializada por menus, objetos clicáveis e sequências lineares de navegação.

Por esse motivo, Sims (1997) destaca que a interatividade pode ser distinguida em níveis diferentes, que são os seguintes: objeto, quando ao clicar, ocorre alguma forma de resposta audiovisual; linear, quando é permitido mover-se apenas para frente ou para trás; de suporte, que é o retorno fornecido pelo sistema e pode variar desde simples mensagens de ajuda até complexos sistemas tutoriais; de atualização, quando pode ocorrer um diálogo entre o aluno e o conteúdo; construtiva, nos casos onde o aluno pode manipular objetos para alcançar objetivos; reflexiva, quando são registradas as respostas inseridas pelos alunos e é permitido que sejam visualizadas as respostas anteriores; de simulação, quando as escolhas individuais do aluno determinam a sequência do treinamento; hiperlinkada, quando o aluno tem acesso a informações nas quais poderá navegar à vontade; contextual não-imersiva, aquela em que o aluno é transportado a um 
contexto onde pode realizar tarefas; virtual imersiva, quando o aluno é inserido virtualmente em um mundo no qual o computador responde a ações e movimentos. É importante ressaltar que os eventos não são mutuamente exclusivos, mas podem agir de forma integrada aumentando a interação.

Percebe-se que as interatividades objetiva, linear e de suporte servem como recursos ao funcionamento do sistema, ajudando o aluno na navegação e que as alternativas que oferecem níveis de interatividade que mais podem produzir situações propícias aos aprendizados são a contextual não-imersiva e a virtual imersiva.

A interatividade de atualização pode apresentar-se em sistemas bastante complexos, dependendo do tamanho do banco de dados disponível. É possível projetar desde um simples perguntas e respostas, até um robô de conversação de inteligência artificial. Mesmo assim, para a aprendizagem do aluno, esse grau de complexidade pode não apresentar relevância, pois, de qualquer uma das formas a interatividade limita-se a respostas prontas buscadas no sistema. Já no caso da interatividade reflexiva, as respostas apresentadas pelo sistema têm origem na escrita de outros alunos, o que proporciona certo grau de interação com os colegas.

Sobre a interatividade hiperlinkada, observa-se que, mesmo que os links ofereçam ao aluno uma grande quantidade de informação, esse tipo de interatividade pode restringi-lo às opções disponibilizadas. Assim, ela pode o desmotivar de buscar por outros conteúdos disponíveis na rede, limitando sua autonomia.

Sims (1997) afirma que em todas as interações, quanto mais a atualização estiver relacionada à resposta individual do aluno, mais esforço será preciso em termos de design e desenvolvimento. Isso se aplica, especialmente, às interatividades construtivas, de simulação, contextual não-imersiva e virtual imersiva, onde a construção gráfica é necessariamente mais elaborada. Nesses casos, os níveis de interatividade e as possibilidades de atuação do aluno frente ao material aumentam proporcionalmente ao aprimoramento de design e tecnologia de cada interface.

De acordo com Sims (1997), quanto maior o nível de interatividade, maior requinte é necessário em termos de design. Ele ainda afirma que "concentrando-se no projeto do conteúdo didático, do design gráfico e da comunicação para implementar interações que motivem e envolvam o aluno, o contínuo sucesso funcional e a eficácia das aplicações interativas de ensino estará assegurado". Dessa afirmação pode-se entender que não é suficiente ter à disposição o recurso tecnológico. Precisa-se, na realidade, de um planejamento adequado do conteúdo e do design da interface.

\section{Considerações finais}

Atualmente, observa-se que boa parte das relações humanas têm se dado por meio de interfaces. No trabalho, na pesquisa, no comércio e mesmo no lazer, muitas das atividades e da comunicação são mediadas pela tecnologia digital. Diante dessa nova atitude, estudos têm surgido que apresentam diversos métodos e princípios para orientação do desenvolvimento de interfaces, no sentido de atender a necessidades ergonômicas $^{10}$ e cognitivas dos usuários (Norman, 2004; Cybis, W. Betiol, A. Faust, F., 2007).

As pesquisas na área têm promovido interfaces de melhor qualidade. Isso se deve, também, a expectativa do usuário, que tem se tornado mais exigente. Normalmente, quando um produto é lançado, seu valor está na inovação, e certo grau de esforço é admitido pelo usuário em prol do benefício de seu uso. Contudo, no contexto atual, a oferta de bons produtos já é grande, e o usuário está menos tolerante com interfaces complicadas (Nielsen, 2007). 
A sofisticação em termos tecnológicos, entretanto, não é garantia de obtenção de um material efetivamente educacional. O desenvolvedor de um MED precisa estar atento para utilizar as opções interativas que sejam mais adequadas aos seus objetivos e que tragam maior proveito aos educandos.

Os MEDs possibilitam o desenvolvimento de conteúdos que incentivam a manipulação, transformação, busca individual da informação, julgamento, criação e descoberta de novas perspectivas. Dessa forma, entende-se que os MEDs, quando desenvolvidos e aplicados com vistas à interação entre sujeito e objeto, podem proporcionar situações em que o aluno desenvolva capacidade argumentativa e reflexiva, construindo novas habilidades e conhecimentos. Para tanto, é preciso que os materiais sejam projetados segundo um planejamento pedagógico, utilizando recursos tecnológicos adequados aos objetivos propostos e observando, também, princípios de design de interface.

\section{Notas de Texto}

\footnotetext{
${ }^{1}$ http://portal.mec.gov.br/index.php?option=com_content\&task=view\&id=11580

${ }^{2} \mathrm{http}$ ://rived.mec.gov.br/site_objeto_lis.php. Acesso em março de 2011.

3 http://www.ieeeltsc.org:8080/Plone/working-group/learning-object-metadata-workinggroup-12/learning-object-metadata-lom-working-group-12. Acesso em março de 2011. ${ }^{4}$ Learning Technology Standards Committee - http://ltsc.ieee.org/wg12/. Acesso em março de 2011.

${ }^{5}$ ARIADNE Foundation for the European Knowledge Pool - http://www.ariadneeu.org/. Acesso em março de 2011.

${ }^{6}$ IMS Global Learning Consortium, Inc. - http://www.imsproject.org/metadata/. Acesso em março de 2011.

${ }^{7}$ http://www.adlnet.gov/Technologies/scorm/default.aspx . Acesso em julho de 2011.

${ }^{8}$ Usuário: (1) Aquele que utiliza um serviço de computação ou de telecomunicações. (2) Qualquer pessoa ou entidade que utiliza os serviços de um sistema de processamento de dados [...] (Sawaya, 1999).

${ }^{9}$ [...] “conjunto de nós ligados por conexões. Os nós podem ser palavras, páginas, imagens, gráficos ou partes de gráficos, seqüências sonoras, documentos completos que podem eles mesmos ser hipertextos. Os itens de informação não são ligados

linearmente, com em uma corda com nós, mas cada um deles ou a maioria, estende suas conexões em estrela, de modo reticular" (Lévy, 1993).

${ }^{10}$ A ergonomia "visa proporcionar eficácia e eficiência , além do bem estar e saúde do usuário, por meio da adaptação do trabalho ao homem" (Cybis, W. Betiol, A. Faust, F., 2007).
}

\section{Referências Bibliográficas}

AMANTE, L.; MORGADO, L. Metodologia de Concepção e Desenvolvimento de Aplicações Educativas: o caso dos materiais hipermedia. In: Discursos, II Série, n especial, PP. 125-138, Universidade Aberta, 2001.

BEHAR, P.A. (orgs.) Modelos Pedagógicos em Educação a Distância. Porto Alegre: Artmed, 2009. 
CYBIS, W. BETIOL, A. FAUST, F. Ergonomia e usabilidade: conhecimentos, métodos e aplicações. São Paulo: Novatec Editora. 2007.

FILATRO, A. Design Instrucional na prática. São Paulo : Pearson Education do Brasil. 2008.

FILATRO, A. As teorias pedagógicas fundamentais em EAD. In: LITTO, F. FORMIGA M. (orgs) Educação a distância : o estado da arte. São Paulo. Pearson Education do Brasil, 2009.

GRUDIN, J. The computer reaches out: the historical continuity of interface design. In Proceedings of CHI'90. 1990. p. 216-268.

HOLMBERG, B. 1986. Growth and Structure of Distance Education. London: Croom-Helm.

IEEE. Learning Technology Standards Committee (LTSC). Draft standard for learning object metadata (IEEE 1484.12.1-2002). Jul. 2002. Disponível em: $<\mathrm{http} / / /$ ltsc.ieee.org/wg12>. Acesso em maio de 2010.

JOHNSON, S. Cultura da interface: como o computador transforma nossa maneira de criar e comunicar. Rio de Janeiro: Jorge Zahar Ed. 2001.

KERCKHOVE, D. In: Odille Fillion. A era da interatividade. Tradução de Paulo Migliacci. Folha de São Paulo, Caderno Mais. São Paulo, 14 jan. 2001.

LAUREL, B. Computers As Theatre. Addition-Wesley. 1993.

LEMOS, A. Cibercultura, tecnologia e vida social na cultura contemporânea. Porto Alegre: Sulina, 2002.

LÉVY, P. As tecnologias da inteligência. São Paulo: Editora 34, 1993.

MACHADO JÚNIOR, F. Interatividade e interface em um ambiente virtual de aprendizagem. Passo Fundo. Ed. IMED, 2008.

MATTAR, J. Interatividade e aprendizagem. In: LITTO, F. FORMIGA M. (orgs) Educação a distância : o estado da arte. São Paulo. Pearson Education do Brasil, 2009.

MARTINS, B; WINCKLER, R. Objetos de aprendizado: um novo modelo direcionado ao ensino a distância. 2004. Acesso em janeiro de 2010, disponível em: http://www.universia.com.br/ead/materia.jsp?materia=5938

MOORE, M. Three types of interaction. In: American Jornal of Distance Education, v.3, n.2, $\quad$ p. 1-6, 1989. Disponível em: <http://www.ajde.com/Contents/vol3_2.htm\#editorial>. Acesso em janeiro de 2011.

MEC. Referenciais de Qualidade para Educação Superior a Distância. 2007. 
Acesso em dezembro de 2009. Disponível em:

$<$ http://portal.mec.gov.br/index.php?option=com_content $\&$ view=article\&id=12777\%3

Areferenciais-de-qualidade-para-ead \&catid=193\%3Aseed-educacao-a-

distancia\&Itemid=865>.

NIELSEN, J; LORANGER, H. Usabilidade na Web. Rio de Janeiro: Elsevier, 2007.

NORMAN, D.A. Emotional Design: why we love (or hate) everyday things. New York: Basic Books, 2004.

PIAGET, J. Aprendizagem e conhecimento. Rio de Janeiro: Freitas Bastos, 1974.

PIAGET, J. Biologia e conhecimento. 2ed. Petrópolis: vozes, 1996.

PIAGET, J. Epistemologia genética. 3ed. São Paulo: Martins Fontes, 2007.

PREECE, J. ROGERS, Y. SHARP, H. Design de Interação: além da interação homemcomputador. Porto Alegre: Bookman. 2005.

SAWAYA, M. R. Dicionário de informática e internet: inglês - português. São Paulo: Nobel. 1999.

SILVA, M. Sala de aula interativa. Rio de Janeiro. Quartet, 2002.

SILVA, R. FERNANDEZ, M. Recursos informáticos projetados para o ensino de ciências: bases epistemológicas implicadas na construção e desenvolvimento de objetos de aprendizagem. In: PRATA, C. NASCIMENTO, A. Objetos de aprendizagem: uma proposta de recurso pedagógico. Brasília: MEC, SEED, 2007.

SIMS, R. Interactivity: a Forgotten Art? Computer in Human Behavior, v13 n2 p15780 May 1997. Acesso em janeiro de 2010, disponível em:

http://www2.gsu.edu/ wwwitr/docs/interact/

TAROUCO, L.; FABRE, M.; TAMUSIUNAS, F. Reusabilidade de objetos educacionais. Acesso em janeiro de 2010, disponível em:

http://www.cinted.ufrgs.br/renote/fev2003/artigos/marie_reusabilidade.pdf 